Revista de

Contabilidade e

Organizações

www.rco.usp.br
DOI: http://dx.doi.org/10.11606/rco.v7i18.55429
Journal of

Accounting and

Organizations

\title{
Escolha de práticas contábeis: um estudo sobre propriedades para investimento em empresas brasileiras não financeiras de capital aberto
}

\author{
Thiago de A. Costa ${ }^{\mathrm{a}}$; Adolfo H. C. e Silva ${ }^{\mathrm{b}}$; Luiz da C. Laurencel ${ }^{\mathrm{b}}$ \\ ${ }^{a}$ Mestrado em Ciências Contábeis - Universidade do Estado do Rio de Janeiro \\ ${ }^{b}$ Faculdade de Administração e Finanças - Universidade do Estado do Rio de Janeiro.
}

\section{Informações do Artigo}

Histórico do Artigo

Recebido: 28 de abril de 2013

Aceito: 10 de outibro de 2013

Palavras chave:

Propriedades para Investimento

Gerenciamento de Resultado

Escolha de Práticas Contábeis

Normas Internacionais de Contabilidade

Valor Justo

\begin{abstract}
Resumo
O objetivo do artigo foi analisar os incentivos econômicos para seleção do método (custo ou valor justo) de mensuração contábil das propriedades para investimento por parte das empresas brasileiras não financeiras de capital aberto. Foi realizada a análise quantitativa através de estatística univariada (teste de diferença de média Mann-Whitney U e teste de proporções) e multivariada (regressão logística) para análise de 36 empresas com propriedades para investimento. Os resultados demonstram que apenas 14 empresas (39\%) optaram pelo método do valor justo para mensuração de suas propriedades para investimento. A análise univariada e multivariada dos dados permite concluir que apenas a variável "receita líquida" foi estatisticamente significativa para explicar o método de mensuração das propriedades para investimento escolhido pelas empresas. Em geral, as empresas com menor receita líquida apresentam maior probabilidade de utilizar o método de valor justo. O presente estudo é relevante por dois aspectos principais: (a) apresenta evidências complementares (à linha de pesquisa accounting choice) sobre a escolha de práticas contábeis realizadas pelos administradores de empresas no Brasil após a adoção das normais internacionais de contabilidade, demonstrando os incentivos econômicos que influenciam as empresas a adotarem determinadas práticas dentro desse novo cenário contábil; e (b) permite conhecer os principais aspectos da implementação do CPC 28 (Propriedades para Investimento) no primeiro ano de adoção integral das normas internacionais de contabilidade.
\end{abstract}

Copyright (C) 2013 FEA-RP/USP. Todos os direitos reservados

\section{INTRODUÇ̃̃O}

Em 28 de Dezembro de 2007 foi aprovada a lei $\mathrm{n}^{\circ}$ 11.638, que estabeleceu que as empresas brasileiras passariam a utilizar o padrão contábil internacional definido de acordo com as normas do IFRS (International Financial Reporting Standards). A adoção de um padrão contábil internacional promoveu mudanças significativas no tratamento contábil de diversos itens das demonstrações contábeis.

Dentre os 43 pronunciamentos contábeis emitidos pelo Comitê de Pronunciamentos Contábeis - CPC, órgão responsável no Brasil por traduzir e adaptar as normas internacionais de contabilidade, o Pronunciamento Técnico CPC 28 (correspondente ao International Accounting Standard - IAS 40) permitiu que as empresas escolhessem entre o método de custo e o método de

Autor Correspondente: Tel +55 21 2334-0662

E-mail : T. A. Costa (thiago.abreu.adm@gmail.com); A. H. C. Silva (adolfocoutinho@uol.com.br); L.C. Laurencel (1laurenc.ntg@terra.com.br).

Universidade do Estado do Rio de Janeiro, Faculdade de Administração e Finanças - FAF.Rua São Francisco Xavier, 524, $9^{\circ}$. Andar, Bloco E, Maracanã 20550013 - Rio de Janeiro, RJ - Brasil valor justo para mensuração das propriedades para investimento (imóveis e terrenos) utilizadas para obter renda. Esse pronunciamento introduziu uma forma completamente diferente de mensuração do padrão contábil vigente anteriormente no Brasil (que permitia apenas o método de custo).

Nesse contexto, o objetivo do artigo foi analisar os incentivos econômicos para seleção do método (custo ou valor justo) de mensuração contábil das propriedades para investimento por parte das empresas brasileiras não financeiras de capital aberto. Adicionalmente, como objetivo secundário da pesquisa, buscou-se: (a) identificar as empresas impactadas pelo CPC 28 e seus respectivos setores de atividades; (b) demonstrar o método contábil preferido pelas empresas para avaliação das propriedades para investimento; e (c) analisar a qualidade da evidenciação contábil vis-à-vis a exigência mínima de divulgação estabelecida no CPC 28.

Considerando que o Brasil passou recentemente pelo processo de convergência para as normas internacionais e que os administradores também tiveram a opção de escolher o método contábil para avaliação das propriedades para investimento, optou-se por replicar no Brasil a mesma análise já realizada em outros países, tais como Portugal, França, Alemanha e Reino Unido. A pesquisa é relevante na medida em que analisa o tema 
em um contexto político, econômico e social diferente, demonstrando a realidade específica observada no Brasil.

O presente estudo é relevante por dois aspectos principais: (a) apresenta evidências complementares (à linha de pesquisa accounting choice) sobre a escolha de práticas contábeis realizadas pelos administradores de empresas no Brasil após a adoção das normais internacionais de contabilidade, demonstrando os incentivos econômicos que influenciam as empresas a adotarem determinadas práticas dentro desse novo cenário contábil; e (b) permite conhecer os principais aspectos da implementação do CPC 28 (Propriedades para Investimento) no primeiro ano de adoção integral das normas internacionais de contabilidade.

A contribuição do presente estudo pode ser destacada em dois planos: (a) no plano acadêmico, o estudo demonstra a importância da análise das práticas contábeis (política contábil) adotadas pelas empresas e seus respectivos efeitos, em complemento aos estudos que buscam apenas identificar, através de modelos empíricos, as acumulações discricionárias (discricionary accruals) observadas nas demonstrações contábeis; (b) no plano empírico, ao reunir informações sobre os tipos de escolhas de práticas contábeis realizadas pelos administradores na aplicação do CPC 28, o estudo dá a chance para que os órgãos reguladores, especialmente o Comitê de Pronunciamentos Contábeis, reflitam sobre a utilidade em se permitir duas formas distintas de mensuração para as propriedades para investimento detidas por empresas brasileiras. Como pode ser observado, os ajustes decorrentes do CPC 28 podem produzir impactos significativos nas demonstrações contábeis das empresas brasileiras, permitindo que empresas do mesmo setor de atividade adotem praticas contábeis distintas para mensurar suas propriedades para investimento, o que pode prejudicar significativamente a comparabilidade das demonstrações contábeis. Nesse sentido, é importante lembrar que o órgão normatizador internacional (IASB - International Accounting Standard Board) permitiu a utilização de dois métodos de mensuração distintos somente em função da existência de países com mercados menos desenvolvidos que poderiam apresentar dificuldades de mensuração pelo valor justo desses ativos, e não em função das características das empresas em si. Considerando que o método do valor justo é preferível em relação ao método de custo, conforme destacado pelo IASB, o Comitê de Pronunciamentos Contábeis poderia avaliar a possibilidade de restringir o método de mensuração das propriedades para investimento no Brasil como sendo o método do valor justo. Tal constatação também tem implicações práticas para os analistas de mercado e para as agências de risco de crédito que utilizam as demonstrações contábeis como base para suas análises.

O restante do artigo está estruturado da seguinte forma: a segunda parte apresenta a revisão de literatura, a terceira parte descreve os procedimentos metodológicos adotados na identificação das empresas, coleta dos dados e análise dos resultados, a quarta parte analisa os resultados e a quinta parte apresenta as considerações finais do estudo.

\section{REFERENCIAL TEÓRICO}

\subsection{Escolha De Práticas Contábeis}

Com a adoção das normas internacionais de contabilidade em diversos países no mundo (incluindo o Brasil), verifica-se o surgimento de novos estudos com o intuito de analisar o impacto da implementação das novas normas sob diversos enfoques, como por exemplo, análise do impacto (a) no custo de capital do capital das empresas, (b) na relevância da informação contábil para o mercado de capitais, e (c) na comparabilidade da informação contábil entre empresas do mesmo setor ou concorrentes.

Devido à norma internacional permitir, em diversos casos, a adoção de procedimentos contábeis distintos para a contabilização de um mesmo item, surge também a oportunidade de se desenvolver novos estudos classificados na literatura contábil como accounting choice (escolha de práticas contábeis).

Fields, Lys e Vincent (2001, p.256), conceituam accounting choice como:

"Uma escolha contábil é qualquer decisão que tem o propósito de influenciar (tanto a forma como a essência) a saída de um sistema contábil de forma particular, incluindo não apenas as demonstrações financeiras publicadas de acordo com os princípios contábeis vigentes, como também as declarações de imposto e exigências regulatórias ${ }^{1}$." (grifo nosso)

De acordo com Ronen e Yaari (2008, p. 31), as escolhas contábeis permeiam os relatórios contábeis e podem ser dos seguintes tipos: (a) escolha do método de mensuração permitida pelas normas contábeis vigentes (PEPS ou média ponderada como o método de avaliação do estoque, por exemplo); (b) escolha do momento de adoção de um novo padrão contábil (quando permitido pela nova norma); (c) julgamento que influencia estimativas contábeis (cálculo da depreciação e provisões, por exemplo); (d) forma de classificação de determinados itens contábeis; (e) estruturação de operações (atividades com impacto no fluxo de caixa e na contabilidade); (f) momento do reconhecimento de receitas e despesas; entre outras.

De acordo com a literatura de accounting choice, as escolhas de práticas contábeis feitas pelos administradores não são realizadas de maneira imparcial, pois são influenciadas por diversos incentivos econômicos (contratuais ou não) existentes. De acordo com Silva e Sancovschi (2007), a teoria positiva da contabilidade busca explicar e prever as escolhas de práticas contábeis tendo como base a ideia de que os indivíduos agem de acordo com seus interesses pessoais, objetivando maximizar o bem-estar próprio (Abordagem Oportunística). Essa ideia corrobora a afirmação de que as escolhas contábeis não são imparciais, visto que para alcançar determinados interesses, os administradores preferem determinadas práticas contábeis em detrimento de outras.

Segundo Watts e Zimmerman (1990), a teoria positiva da contabilidade procura explicar a escolha de práticas contábeis através de três hipóteses:

a) hipótese dos planos de incentivo;

b) hipótese do nível de endividamento; e

c) hipótese dos custos políticos.

1 "An accounting choice is any decision whose primary purpose is to influence (either in form or substance) the output of the accounting system in a particular way, including not only financial statements published in accordance with GAAP, but also tax returns and regulatory filings." 
Silva e Sancovschi (2007) esclarecem que as empresas tendem a escolher práticas contábeis que aumentem o resultado quando existem planos de remuneração variável (incentivo) aos administradores vinculados ao desempenho (performance) contábil e altos níveis de endividamento. Por outro lado, as empresas realizam escolhas contábeis que diminuem o resultado para evitar (ou mitigar) eventuais custos políticos decorrentes da maior exposição.

O quadro a seguir detalha as características das empresas e o comportamento esperado em termos de escolhas de práticas contábeis de acordo com a literatura analisada.

Quadro 1. Descrição dos incentivos econômicos para a realização de escolhas contábeis

\begin{tabular}{|c|c|}
\hline $\begin{array}{c}\text { Incentivos } \\
\text { Econômicos }\end{array}$ & Descrição \\
\hline$\stackrel{0}{0}$ & $\begin{array}{l}\text { Os administradores de grandes empresas } \\
\text { tendem a escolher práticas contábeis que } \\
\text { diminuem o resultado para diminuírem seus } \\
\text { custos políticos. As empresas com maior porte } \\
\text { estão mais sujeitas à supervisão do Governo, } \\
\text { fazendo com que as mesmas adotem práticas } \\
\text { contábeis mais conservadoras objetivando } \\
\text { diminuir os custos políticos (WATTS e } \\
\text { ZIMMERMAN, 1990; CONCEIÇÃO, 2009). }\end{array}$ \\
\hline 逽 & $\begin{array}{l}\text { Um nível de endividamento alto incentiva os } \\
\text { administradores a adotarem práticas contábeis } \\
\text { que aumentou o resultado das empresas. Ao } \\
\text { adotar essas práticas, os administradores } \\
\text { reduzem a probabilidade de violação de } \\
\text { covenats (cláusulas) contratuais. (WATTS } \\
\text { e ZIMMERMAN, 1990; FIELDS; LYS; } \\
\text { VINCENT, 2001; SILVA, 2008) }\end{array}$ \\
\hline 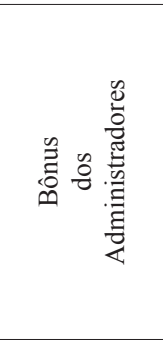 & $\begin{array}{l}\text { A existência de pagamento de planos de } \\
\text { remuneração variável (bonus plan) para a } \\
\text { alta administração baseados em resultados } \\
\text { contábeis aumenta a probabilidade de } \\
\text { os administradores escolherem práticas } \\
\text { contábeis que aumentem o resultado, } \\
\text { objetivando atingir as metas estabelecidas } \\
\text { (WATTS; ZIMMERMAN, 1990; SILVA; } \\
\text { SANCOVSCHI, 2007; RONEN; YAARI, } \\
\text { 2008). }\end{array}$ \\
\hline 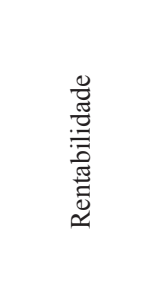 & $\begin{array}{l}\text { Índices de rentabilidade são utilizados por } \\
\text { diversos stakeholders como medida de } \\
\text { desempenho das empresas. Sabendo que } \\
\text { os stakeholders têm expectativas sobre o } \\
\text { desempenho da empresa, os gestores são } \\
\text { incentivados a escolher práticas contábeis } \\
\text { que contribuam para alcançar o desempenho } \\
\text { previsto pelos stakeholders (RONEN; } \\
\text { YAARI, 2008). }\end{array}$ \\
\hline 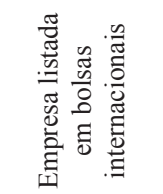 & $\begin{array}{l}\text { Empresas que negociam suas ações em bolsas } \\
\text { internacionais (cross-listing) tendem a adotar } \\
\text { práticas contábeis mais conservadores, pois } \\
\text { estão sob regimes mais rigorosos (DEMARIA; } \\
\text { DUFOUR, 2008). }\end{array}$ \\
\hline
\end{tabular}

Fonte: Elaborado pelos autores

Os incentivos econômicos mencionados na tabela acima refletem as razões mais recorrentes identificadas na literatura de accounting choice. Os três primeiros mencionados referem-se à teoria positiva de contabilidade proposta por Watts e Zimmerman (1990). A rentabilidade, como indicado por Ronen e Yaari (2008) relacionase às expectativas das partes interessadas na empresa (stakeholders), bem como, em geral, são medidas de interesse dos administradores das empresas. Por fim, a dupla listagem em mercados de capitais com normas contábeis diferentes também influencia as escolhas de práticas contábeis realizadas pelas empresas. Nesse contexto, sempre que possível, uma empresa tenderá a adotar uma prática contábil aceita nos dois países para mitigar custos de conversão das demonstrações contábeis.

Ao escolher práticas contábeis de acordo com os incentivos econômicos existentes, pode-se entender que a empresa está gerenciando o seu resultado ou outras métricas contábeis relevantes.

\subsection{Mensuração das Propriedades Para Investimento $\left(C P C n^{\circ} 28\right)$}

De acordo com o Pronunciamento Técnico CPC 28 (2009, p.3), propriedade para investimento "é a propriedade (terreno ou edifício - ou parte) mantida pelo proprietário (ou arrendatário em arrendamento financeiro) para auferir aluguel ou para valorização do capital ou para ambas". Essa definição é importante, pois não inclui outros itens, como propriedades destinadas à venda, propriedades ocupadas pelo proprietário e ativos biológicos

O CPC 28 prevê duas formas de mensuração das propriedades para investimento: (a) método do custo; ou (b) método do valor justo. Se a empresa optar por mensurar suas propriedades para investimento pelo custo deve divulgar o valor justo dessas propriedades em notas explicativas.

De acordo com o Basis for Conclusion do International Accounting Standard (IAS) 40 (2009), os motivos que foram levados em consideração para manter dois métodos de mensuração para as propriedades para investimento foram: (a) permitir que os elaboradores das demonstrações financeiras e os usuários da informação contábil ganhem experiência com o modelo de valor justo; e (b) dar tempo para o amadurecimento dos mercados imobiliários e de profissionais de avaliação de propriedades para investimento.

Caso a empresa opte por avaliar suas propriedades a valor justo, as variações no valor justo devem ser reconhecidas no resultado do período em que ocorreram ${ }^{2}$. O CPC 28 (2009, p. 12) também versa sobre a forma de apuração do valor justo. De acordo com o item 44 do pronunciamento:

A melhor evidência de valor justo é dada por preços correntes em mercado ativo de propriedades semelhantes no mesmo local e condição e sujeitas a arrendamentos e outros contratos semelhantes. A entidade trata de identificar quaisquer diferenças de natureza, local ou condição da propriedade, ou nos termos contratuais dos arrendamentos e de outros contratos relacionados com a propriedade. (Fonte: Item 44 do CPC 28) (grifo nosso)

2 O Basis for Conclusion do IAS 40 (2009) esclarece que as variações do valor justo devem ser reconhecidas no resultado visto que o valor justo fornece uma visão relevante e transparente sobre o desempenho das propriedades para investimento. Além disso, o reconhecimento dessa variação no capital próprio poderia gerar alguns problemas, como o descompasso que ocorreria, já que a renda gerada pela propriedade para investimento é reconhecida no resultado. 
Na falta de um mercado ativo, o CPC 28 (2009, p. 12) apresenta a seguinte alternativa para avaliar o valor justo da propriedade para investimento.

$\mathrm{Na}$ ausência de preços correntes em mercado ativo do gênero descrito no item 45 , a entidade considera a informação proveniente de uma variedade de fontes, incluindo:

(a) preços correntes em mercado ativo de propriedades de diferente natureza, condição ou localização (ou sujeitas a diferentes arrendamentos ou outros contratos), ajustados para refletir essas diferenças;

(b) preços recentes de propriedades semelhantes em mercados menos ativos, com ajustes para refletir quaisquer alterações nas condições econômicas desde a data das transações que ocorreram a esses preços; e

(c) projeções de fluxos de caixa descontados com base em estimativas confiáveis de futuros fluxos de caixa, suportadas pelos termos de qualquer arrendamento e de outros contratos existentes e (quando possível) por evidência externa tal como rendas correntes de mercado de propriedades semelhantes no mesmo local e condição, e usando taxas de desconto que reflitam avaliações correntes de mercado quanto à incerteza na quantia e tempestividade dos fluxos de caixa. (Fonte: Item 45 do CPC 28)

O CPC 28 também incentiva a obtenção do valor justo através de avaliadores independentes, sendo que as premissas utilizadas para o seu cálculo devem ser evidenciadas em notas explicativas.

Deve-se destacar que a escolha contábil atrelada à propriedade para investimento não tem efeito direto no caixa da empresa, bem como, não há impacto fiscal associado. A adoção do valor justo impacta apenas o lucro da empresa, e as medidas associadas ao mesmo.

\subsection{Estudos Anteriores}

Considerando que as normas do IFRS (International Financial Reporting Standards, emitidas pelo International Accounting Standard Board - IASB), permitem que as empresas escolham entre dois métodos contábeis (custo histórico e valor justo) para a mensuração de suas propriedades para investimento, surge a oportunidade para realização de estudos sobre os incentivos econômicos para a realização de escolhas contábeis (accounting choice). Após um levantamento, constatou-se que já existem estudos sobre escolha de práticas contábeis envolvendo propriedades para investimento, porém não são numerosos e nenhum deles foi realizado no Brasil.

Entre os estudos identificados, podemos citar o de Muller III, Riedl e Sellhorn (2008), que investigaram as causas e consequências da decisão das empresas de fornecer ou não o valor justo de suas propriedades para investimentos no período anterior à adoção do IFRS, e o efeito sobre as empresas que não forneceram informações sobre o justo valor durante a transição para o IFRS. Utilizando uma amostra de 100 empresas de capital aberto da Europa no ano de 2006 que possuíam propriedades para investimento, o estudo encontrou evidências de que a demanda dos investidores pelo valor justo aumentou a probabilidade de as empresas divulgarem o valor justo antes da adoção obrigatória do IFRS. Também foram encontradas evidências de que as empresas que não divulgam o valor justo de suas propriedades para investimento possuem maior nível de assimetria informacional. $O$ estudo não encontrou evidências de que a adoção obrigatória do IFRS diminuiu a assimetria informacional.

Demaria e Dufour (2008) estudaram, após a adoção do IFRS, as empresas francesas que adotaram o valor justo em relação às propriedades para investimento, aos ativos intangíveis e ao custo atribuído do ativo imobilizado; além de procurar evidências sobre os fatores determinantes para essa escolha. Utilizando uma amostra de 107 empresas francesas de capital aberto no ano de 2005 , os autores concluíram que $38 \%$ das empresas adotaram o valor justo após a adoção do IFRS, sendo que a o teste estatístico multivariado (regressão logística) apontou que o fator que influenciou a escolha do valor justo foi o fato de a empresa pertencer ao segmento da indústria financeira.

Conceição (2009) investigou a escolha pelo valor justo em empresas portuguesas, após a adoção das normas internacionais, em relação aos ativos fixos, intangíveis e propriedades para investimento, além de identificar os incentivos responsáveis por essas escolhas. Utilizando uma amostra de 50 empresas portuguesas de capital aberto no ano de 2005, o estudo concluiu que a adesão ao valor justo não foi significativa ( $40 \%$ das empresas que possuíam propriedades para investimento optaram por avaliar esses ativos a valor justo). Foram encontradas evidências de que o tamanho da empresa e o endividamento influenciaram a escolha pelo valor justo.

Destaca-se também o estudo elaborado por Christensen e Nikolaev (2009). Os autores desenvolveram um estudo sobre escolha de práticas contábeis envolvendo propriedades para investimento, com uma amostra de 124 empresas de capital aberto do Reino Unido e 151 empresas de capital aberto da Alemanha, sendo que todas elas possuíam propriedades para investimento. Utilizando uma análise multivariada através de regressão logística, os autores encontraram evidências de que as empresas com maiores dívidas tendiam a adotar o valor justo para mensurar suas propriedades para investimento. Além disso, o estudo mostra que $23 \%$ das empresas alemães que possuem propriedades para investimento adotaram o método do valor justo para mensurar esses imóveis, enquanto que no Reino Unido $77 \%$ das empresas não financeiras adotam o valor justo em suas propriedades para investimento.

Em resumo, os estudos anteriores demonstram que as empresas de um mesmo país têm realizado escolhas diferentes quanto ao método de mensuração das propriedades para investimento, sendo que as análises dos incentivos econômicos para a realização de tais escolhas não são conclusivos. Em dois dos estudos apontou-se o nível de endividamento das empresas como o determinante para a adoção do método do valor justo.

No Brasil, como o CPC 28 só passou a ser obrigatoriamente utilizado a partir do final do exercício de 2010, estudos dessa natureza envolvendo propriedades para investimento só puderam ser realizados no Brasil a partir desse período. Esta pode ser uma das justificativas para o fato de não termos encontrado estudos dessa natureza no Brasil para as empresas não financeiras. 


\section{METODOLOGIA}

\subsection{Seleção Da Amostra}

Para alcançar o objetivo estabelecido, foi necessário identificar as empresas não financeiras de capital aberto que possuíam propriedades para investimento. Foram escolhidas empresas de capital aberto devido à facilidade de acesso às informações, já que os demonstrativos contábeis são públicos e disponíveis no site da CVM (Comissão de Valores Mobiliários). Para determinar quais empresas atendiam a esse requisito, foi consultada, em agosto de 2011, a base de dados Economática $(C$ para se obter a lista de empresas não financeiras de capital aberto. Em seguida, foram consultadas as notas explicativas das demonstrações financeiras do ano de 2010 de cada uma dessas empresas para verificar a existência de propriedades para investimento em seus balanços.

De um total de 335 empresas não financeiras de capital aberto analisadas, foram encontradas 37 empresas que atendiam a esse critério, isto é, possuíam propriedades para investimento, sendo que três empresas não indicavam o método de mensuração de suas propriedades para investimento. Porém, ao analisar as demonstrações financeiras dessas três empresas, foi considerado que duas empresas utilizavam o método do custo, enquanto que uma empresa teve de ser excluída da amostra, pois não foi possível identificar o método de mensuração de suas propriedades para investimento. Sendo assim, a amostra final utilizada nesse estudo foi composta por 36 empresas, como demonstrado na tabela 1 .

Tabela 1. Composição da amostra no exercício de 2010

\begin{tabular}{l|c|c}
\hline $\begin{array}{l}\text { Quantidade de empresas com registro } \\
\text { na CVM }\end{array}$ & 335 & $100,0 \%$ \\
\hline $\begin{array}{l}\text { (1) }- \text { ) Empresas que não possuíam } \\
\text { propriedades para investimento }\end{array}$ & $(298)$ & $88,8 \%$ \\
\hline $\begin{array}{l}\text { ( - ) Empresas que não divulgaram } \\
\text { o método de avaliação de suas } \\
\text { propriedades para investimento }\end{array}$ & $\underline{(1)}$ & $\underline{0,3 \%}$ \\
\hline Quantidade de empresas na amostra & 36 & $10,7 \%$ \\
\hline
\end{tabular}

Nota: (1) Dados coletados no site da Economática (C) em Agosto de 2011 .

Fonte: Elaborada pelos autores.

Após a seleção das empresas, todos os dados necessários para a pesquisa foram coletados manualmente e tabulados após análise das demonstrações contábeis e do formulário de referência disponíveis no site da CVM. Deve-se destacar que este procedimento foi necessário devido à ausência de uma base de dados que possuísse todas as informações necessárias para a pesquisa.

\subsection{Análise Dos Resultados}

Inicialmente, foram utilizados testes de diferença de média (Mann-Whitney $U$ ) para verificar se existiam diferenças estatísticas significativas entre as variáveis representativas dos incentivos econômicos analisados (vide métricas contábeis descritas no quadro 2) de acordo com o tipo de escolha contábil feita pela empresa (método do custo ou método do valor justo). O teste Mann-Whitney $U$ foi utilizado já que os testes Kolmogorov-Smirnov e Shapiro Wilk indicaram que os dados não apresentavam distribuição normal.
Em seguida, foi utilizada a análise multivariada (regressão logística) para verificar quais são os incentivos que influenciaram as empresas a adotar o valor justo para mensurar suas propriedades para investimento. Silva (2008) afirma que o modelo logit é predominante nos estudos sobre escolha de práticas contábeis, visto que a variável dependente pode ser mensurada de forma categórica para dois grupos. A regressão proposta no estudo utilizou dados em corte (cross sectional), considerando o ano de 2010.

O modelo utilizado nesse estudo foi:

$\operatorname{logit}(p)=\beta_{0}+\beta_{1}$ Porte $+\beta_{2}$ Dívida $+\beta_{3}$ Rentabilidade $+\beta_{4}$ Bônus $+\beta_{5}$ ADR $+\varepsilon$

$$
\text { Onde, } \quad \operatorname{logit}(p)=\ln (p /(1-p))
$$

A variável dependente é uma variável dicotômica (dummy) na qual foi atribuído 0 (zero) para empresas que utilizam o método do custo (income decreasing) e 1 (um) para empresas que utilizam o método do valor justo (income increasing). Destaca-se que a adoção do método do valor justo, no período de análise, implica no aumento do ativo e do resultado do exercício, e, consequentemente, no patrimônio líquido da empresa (vide informações detalhadas na análise dos resultados). A adoção do método de custo é a opção mais conservadora.

As variáveis explanatórias (independentes) presentes no modelo, as definições (proxies) escolhidas e o sinal esperado para cada uma delas estão descritos no quadro 3.

Quadro 3. Operacionalização das Variáveis Explanatórias (Independentes)

\begin{tabular}{|c|c|c|c|}
\hline Variável & Sigla & Definição & 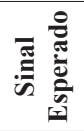 \\
\hline \multirow{2}{*}{ 苛 } & 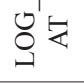 & $\begin{array}{l}\text { Logaritmo do Ativo } \\
\text { Total de } 2010 .\end{array}$ & \multirow{2}{*}{$(-)$} \\
\hline & 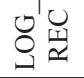 & $\begin{array}{l}\text { Logaritmo da Receita } \\
\text { Líquida de } 2010 .\end{array}$ & \\
\hline \multirow{2}{*}{ 龸 } & $\sum$ & $\begin{array}{l}\text { Passivo Exigível de } 2010 \\
\text { dividido pelo patrimônio } \\
\text { líquido de } 2010 \text {. }\end{array}$ & \multirow{2}{*}{$(+)$} \\
\hline & $\sum_{0}^{2}$ & $\begin{array}{l}\text { Ativo Total de } 2010 \\
\text { dividido pelo patrimônio } \\
\text { líquido de } 2010 \text {. }\end{array}$ & \\
\hline \multirow{2}{*}{ 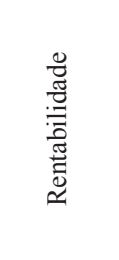 } & $\begin{array}{l}\hat{e} \\
\text { 띵 } \\
2 \\
\approx\end{array}$ & $\begin{array}{l}\text { Lucro Líquido de } 2010 \\
\text { dividido pela média entre } \\
\text { o patrimônio líquido de } \\
2010 \text { e } 2009 .\end{array}$ & \multirow{2}{*}{$(+)$} \\
\hline & 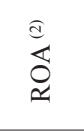 & $\begin{array}{l}\text { Lucro Líquido de } 2010 \\
\text { dividido pela média } \\
\text { entre o ativo total de } \\
2010 \text { e } 2009 .\end{array}$ & \\
\hline 宅 & $\overbrace{0}^{n}$ & $\begin{array}{l}0 \text { (zero) caso a empresa } \\
\text { não paga bônus aos } \\
\text { administradores e } 1 \\
\text { (um) para empresas } \\
\text { que paga bônus aos } \\
\text { administradores. }\end{array}$ & $(+)$ \\
\hline 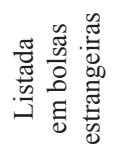 & $\begin{array}{l}\widehat{0} \\
\text { 会 } \\
\text { \& }\end{array}$ & $\begin{array}{c}0 \text { (zero) para as empresas } \\
\text { que não negociam } \\
\text { ADRs e } 1 \text { (um) para as } \\
\text { empresas que negociam } \\
\text { ADRs. }\end{array}$ & $(-)$ \\
\hline
\end{tabular}

Nota: (1) A sigla ROE corresponde ao Retorno sobre o Patrimônio 
Líquido (Return on Equity). (2) A sigla ROA corresponde ao Retorno sobre Ativos (Return on Assets); e (3) A sigla ADR corresponde a títulos públicos emitidos no mercado norte-americano (American Depositary Receipts. Fonte: Elaborado pelos autores

Considerando que as variáveis "porte", "dívida" e "rentabilidade" possuem duas definições operacionais cada e uma correlação alta e estatisticamente significativa, foram testados modelos alternando às referidas variáveis, objetivando atingir todas as combinações possíveis com as variáveis propostas. ${ }^{3}$

As hipóteses testadas na análise univariada e multivariada foram:

$\mathbf{H}_{\mathbf{0}}$ - Não existem diferenças significativas entre a métrica contábil (proxies indicadas no quadro 3) para empresas que adotam o método de custo e para as empresas que adotam o método de valor justo para mensurar as propriedades para investimento.

$\mathbf{H}_{1}$ - Existem diferenças significativas entre a métrica contábil (proxies indicadas no quadro 2) para empresas que adotam o método de custo e para as empresas que adotam o método de valor justo para mensurar as propriedades para investimento.

Adicionalmente, foi realizado o teste qui-quadrado com o objetivo verificar se existem diferenças de proporções, para as empresas que adotaram o método do valor justo, entre as empresas que apuraram lucro ou prejuízo antes e depois dos ajustes decorrentes da adoção do método de valor justo (resultado ajustado e resultado divulgado, respectivamente). $\mathrm{O}$ resultado ajustado corresponde ao valor do resultado divulgado na demonstração do resultado menos o valor da variação do valor justo das propriedades para investimento.

A análise estatística foi realizada através de uma tabela de contingência, onde os grupos são o resultado divulgado e o resultado ajustado, e as categorias são o lucro e o prejuízo.

As seguintes hipóteses foram testadas utilizando o teste de proporções:

$\mathbf{H}_{0}$ - Não existem diferenças na proporção de empresas, que utilizam valor justo, que tiveram lucro e que tiveram prejuízo, de acordo com o resultado considerado (resultado divulgado e resultado ajustado).

$\mathbf{H}_{1}$ - Existem diferenças na proporção de empresas, que utilizam valor justo, que tiveram lucro e que tiveram prejuízo, de acordo com o resultado considerado (resultado divulgado e resultado ajustado).

Destaca-se que as análises estatísticas foram realizadas com apoio do software estatístico SPSS 17 (Statistical Package for the Social Sciences).

Por fim, foi realizada uma análise qualitativa das informações divulgadas pelas empresas tendo como

3 Em relação ao tamanho da amostra, Hair et al. (2005, p. 219) sugerem um mínimo recomendável de cinco observações para cada variável independente. Segundo os autores, os resultados se tornam instáveis quando o tamanho da amostra diminui em relação ao número de variáveis. Adicionalmente, sugere que o menor grupo analisado apresente pelo menos 20 observações, e nunca seja inferior ao número de variáveis independentes do modelo. Os autores também mencionam que não é adequado utilizar grupos com proporções significativamente diferentes (tamanho relativo dos grupos), apesar de não indicar qual é a proporção máxima aceita. Hair et al. (2005, p. 260) apresentam um exemplo da aplicação da regressão logística, em seu livro, no qual a proporção adotada é de 2 para 1 entre os grupos estudados. objetivo verificar o nível de conformidade (compliance) da divulgação de informações em relação às principais exigências de evidenciação do CPC 28

\section{RESULTADOS}

4.1 Empresas Impactadas Pelo CPC 28 e o Método De Mensuração Das Propriedades Para Investimento Escolhido (Escolha Contábil)

A tabela 2 apresenta a distribuição de empresas que possuem propriedades para investimento, de acordo com os seus respectivos setores de atividades, bem como o método de mensuração escolhido. Ao observá-la, nota-se que apenas 36 (11\% do total) das empresas de capital aberto foram impactadas pelo CPC 28 no exercício de 2010 .

Tabela 2. Distribuição das empresas por setor

\begin{tabular}{|c|c|c|c|c|c|c|c|}
\hline \multirow{3}{*}{ Setor } & \multirow{3}{*}{ 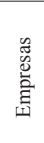 } & \multirow{2}{*}{\multicolumn{2}{|c|}{$\begin{array}{c}\text { Possuem } \\
\text { Propriedade } \\
\text { para } \\
\text { investimento } \\
\end{array}$}} & \multicolumn{4}{|c|}{ Método } \\
\hline & & & & \multicolumn{2}{|c|}{ Custo } & \multicolumn{2}{|c|}{ Valor Justo } \\
\hline & & $\mathrm{N}$ & $\%$ & $\mathrm{~N}$ & $\%$ & $\mathrm{~N}$ & $\%$ \\
\hline $\begin{array}{l}\text { Adm. de Empresas } \\
\text { e Empreendimentos }\end{array}$ & 26 & 6 & $23 \%$ & 2 & $33 \%$ & 4 & $67 \%$ \\
\hline Agro e Pesca & 4 & 1 & $25 \%$ & 1 & $100 \%$ & 0 & $0 \%$ \\
\hline Alimentos e Bebidas & 19 & 0 & $0 \%$ & 0 & N/A & 0 & N/A \\
\hline Comércio & 14 & 2 & $14 \%$ & 1 & $50 \%$ & 1 & $50 \%$ \\
\hline Construção & 32 & 6 & $19 \%$ & 4 & $67 \%$ & 2 & $33 \%$ \\
\hline Eletroeletrônicos & 7 & 0 & $0 \%$ & 0 & N/A & 0 & N/A \\
\hline Energia Elétrica & 41 & 3 & $7 \%$ & 3 & $100 \%$ & 0 & $0 \%$ \\
\hline Locadora de Imóveis & 5 & 5 & $100 \%$ & 3 & $60 \%$ & 2 & $40 \%$ \\
\hline Máquinas Industriais & 5 & 1 & $20 \%$ & 1 & $100 \%$ & 0 & $0 \%$ \\
\hline Minerais não Metálicos & 3 & 0 & $0 \%$ & 0 & N/A & 0 & N/A \\
\hline Mineração & 8 & 0 & $0 \%$ & 0 & N/A & 0 & N/A \\
\hline Papel e Celulose & 6 & 0 & $0 \%$ & 0 & N/A & 0 & N/A \\
\hline Petróleo e Gás & 6 & 1 & $17 \%$ & 0 & $0 \%$ & 1 & $100 \%$ \\
\hline Química & 14 & 0 & $0 \%$ & 0 & N/A & 0 & N/A \\
\hline Siderurgia e Metalurgia & 26 & 1 & $4 \%$ & 1 & $100 \%$ & 0 & $0 \%$ \\
\hline Software e Dados & 2 & 0 & $0 \%$ & 0 & N/A & 0 & N/A \\
\hline Telecomunicações & 14 & 0 & $0 \%$ & 0 & N/A & 0 & N/A \\
\hline Têxtil & 28 & 7 & $25 \%$ & 5 & $71 \%$ & 2 & $29 \%$ \\
\hline Transporte e Serviços & 12 & 0 & $0 \%$ & 0 & N/A & 0 & N/A \\
\hline Veículos e Peças & 17 & 3 & $18 \%$ & 1 & $33 \%$ & 2 & $67 \%$ \\
\hline Outros & 44 & 0 & $0 \%$ & 0 & N/A & 0 & N/A \\
\hline Total & 335 & 36 & $11 \%$ & 22 & $61 \%$ & 14 & $39 \%$ \\
\hline
\end{tabular}

Nota: Foi utilizada a classificação setorial da Economática (C). Os setores administração de empresas e empreendimentos e locadora de imóveis foram segregados do grupo "outros" devido à relevância para o estudo. Fonte: Elaborada pelos autores.

As maiores concentrações de empresas com propriedades para investimentos estão nos setores (a) têxtil (7 empresas); (b) administração de empresas e empreendimentos (6 empresas); (c) construção (6 empresas); e (d) locadora de imóveis (5 empresas). Destaca-se ainda que nove setores de atividades não foram impactados pelo CPC 28, e apenas o setor "locadora de imóveis" teve todas as empresas impactadas 
pelo CPC 28.

Outro aspecto relevante a salientar é que apenas 4 (quatro) empresas impactadas $(12,5 \%$ do total) pertenciam a setores regulados, sendo três empresas do setor de energia elétrica (todas utilizaram o método de custo) e uma empresa do setor de petróleo e gás (que adotou o método de valor justo).

Do total de 36 empresas, 14 delas (39\%) adotaram o valor justo para suas propriedades para investimento. Porém, observa-se que essas empresas não estão necessariamente classificadas nos mesmos setores, fazendo com que dentro de setores econômicos existam empresas que utilizam formas de mensuração diferentes para o mesmo item. Destaca-se aqui um potencial problema de comparabilidade das demonstrações contábeis de empresas do mesmo setor que adotam práticas contábeis distintas para o mesmo tipo de ativo.

As empresas, em suas demonstrações contábeis, devem apenas informar qual é o método utilizado para mensurar suas propriedades para investimento, sem ter que explicar qual a motivação por trás de tal escolha. Porém, uma das empresas demonstrou em notas explicativas uma justificativa para tal escolha. A justificativa está transcrita a seguir:

A Sociedade optou por manter suas propriedades de investimento registradas por valor de custo, por entender que esta seja a informação de melhor qualidade existente para empresas que atuam no setor de investimentos imobiliários com objetivo de renda de locação. Por entender que o valor de mercado dos imóveis pode oscilar substancialmente em virtude de diversas variáveis, entre as quais se destacam o nível das taxas de juros de longo prazo e os níveis de locação praticados no mercado. Por esses motivos o mercado imobiliário tem um padrão de comportamento bastante cíclico que naturalmente se reflete nas avaliações dos imóveis e que traria oscilações importantes de valor para as demonstrações financeiras da Sociedade se ela optasse por valorar as propriedades de investimentos pelo preço de mercado do último ano. (Nota Explicativa das Demonstrações Contábeis de 2010 (grifo nosso).

A tabela 3 compara as escolhas contábeis do método de mensuração das propriedades para investimento das empresas dos países da Europa (analisados no referencial teórico) e do Brasil (objeto de estudo).

Tabela 3. Escolha contábil sobre propriedades para investimento em países da Europa e Brasil

\begin{tabular}{|c|c|c|c|c|c|}
\hline \multirow{3}{*}{ País } & \multirow{3}{*}{ 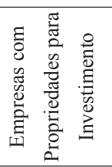 } & \multicolumn{4}{|c|}{ Método } \\
\hline & & \multicolumn{2}{|c|}{ Custo } & \multicolumn{2}{|c|}{ Valor Justo } \\
\hline & & $\mathrm{N}$ & $\%$ & $\mathrm{~N}$ & $\%$ \\
\hline Portugal (1) & 18 & 10 & $60 \%$ & 8 & $40 \%$ \\
\hline França ${ }^{(2)}$ & 33 & 24 & $73 \%$ & 9 & $27 \%$ \\
\hline Alemanha ${ }^{(3)}$ & 151 & 117 & $77 \%$ & 34 & $23 \%$ \\
\hline $\begin{array}{l}\text { Reino Unido } \\
\text { (3) }\end{array}$ & 124 & 28 & $23 \%$ & 96 & $77 \%$ \\
\hline Brasil & 36 & 22 & $61 \%$ & 14 & $39 \%$ \\
\hline
\end{tabular}

Nota: Informações obtidas nos estudos de: (1) Conceição, 2009; (2)

Demaria; Dufour, 2008; (3) Christensen; Nikolaev, 2009.

Fonte: Elaborado pelos autores.

Ao analisarmos as escolhas do método de avaliação das propriedades para investimento das empresas brasileiras comparativamente com as escolhas feitas em outros países da Europa, percebe-se que a maioria das empresas brasileiras de capital aberto prefere avaliar suas propriedades para investimento utilizando o método do custo (61\% das empresas), assim como observado em países como França, Alemanha e Portugal, o que indica que mesmo em contextos econômicos distintos (Brasil, Portugal, França e Alemanha), as escolhas contábeis parecem seguir na mesma direção.

Deve-se destacar que apenas o Reino Unido apresenta um número maior de empresas que utilizam o método do valor justo. Isso pode ser explicado pelo fato de que o padrão contábil utilizado por esse país antes da adoção do IFRS obrigava as empresas a manter suas propriedades para investimento mensuradas a valor justo. Essa prática era diferente daquela adotada pelo Brasil, Alemanha, França e Portugal antes da adoção das normas internacionais, que determinavam a contabilização das propriedades para investimento utilizando o método do custo.

\subsection{Análise Preliminar Dos Incentivos Econômicos (Estatística Univariada)}

A tabela 4 apresenta o resultado do teste de diferenças de média entre as variáveis explanatórias utilizadas no estudo de acordo com o método escolhido para mesurar as propriedades para investimento (método do custo ou método do valor justo).

Tabela 4. Resultado dos Testes Utilizando Estatística Univariada

Painel 1 - Teste de Diferença de Média (Teste Mann-Whitney $\left.U^{a}\right)$ para variáveis quantitativas

\begin{tabular}{|c|c|c|c|c|c|c|}
\hline & & \multicolumn{3}{|c|}{ Valor Médio } & \multirow[b]{2}{*}{ 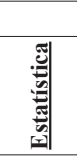 } & \multirow[b]{2}{*}{ 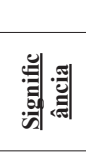 } \\
\hline Variável & $\underline{\mathbf{n}}$ & 평 & 월 & 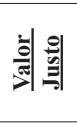 & & \\
\hline LOG_AT & 36 & 2.431 & 2.824 & 2.086 & $-1,103$ & 0,270 \\
\hline $\begin{array}{c}\mathrm{LOG}_{-} \\
\mathrm{REC}\end{array}$ & 36 & 1.036 & 1.508 & 317 & $-2,077$ & $0,038 * *$ \\
\hline Dív1 & 36 & 4,7 & 6,3 & 2,7 & $-0,260$ & 0,795 \\
\hline Dív2 & 36 & 5,6 & 7,2 & 3,7 & $-0,649$ & 0,516 \\
\hline ROA & 36 & $10,0 \%$ & $8,9 \%$ & $12,4 \%$ & $-0,357$ & 0,721 \\
\hline ROE & 36 & $5,8 \%$ & $5,5 \%$ & $6,4 \%$ & $-0,681$ & 0,496 \\
\hline BONUS & 36 & 0,78 & 0,82 & 0,71 & $-0,712$ & 0,471 \\
\hline ADR & 36 & 0,11 & 0,14 & 0,07 & $-0,596$ & 0,551 \\
\hline
\end{tabular}

Painel 2 - Teste de Diferença de Proporções (qui-quadrado) para variáveis dummy

\begin{tabular}{|c|c|c|c|c|}
\hline & Método & Sim & Não & Total \\
\hline \multirow{5}{*}{$\mathrm{ADR}$} & Custo & 18 & 4 & 22 \\
\hline & Valor Justo & 10 & 4 & 14 \\
\hline & Total & 28 & 8 & 36 \\
\hline & $\chi^{2}$ & \multicolumn{3}{|c|}{ Significância } \\
\hline & $0.102^{b}$ & \multicolumn{3}{|c|}{$0,749^{b}$} \\
\hline \multirow{5}{*}{ Bônus } & Custo & 3 & 19 & 22 \\
\hline & Valor Justo & 1 & 13 & 14 \\
\hline & Total & 4 & 2 & 36 \\
\hline & $\chi^{2}$ & \multicolumn{3}{|c|}{ Significância } \\
\hline & $0,004^{b}$ & \multicolumn{3}{|c|}{$0,952^{\mathrm{b}}$} \\
\hline
\end{tabular}


Nota: Log_At é o logaritmo do Ativo Total de 2010, Log_Rec é o logaritmo da Receita Líquida de 2010, Div1 é o Passivo Exigível de 2010 dividido pelo patrimônio líquido de 2010; Div2 é o Ativo Total de 2010 dividido pelo patrimônio líquido de 2010; ROA é o Lucro Líquido de 2010 dividido pela média entre o ativo total de 2010 e o ativo total de 2009; ROE é o Lucro Líquido de 2010 dividido pela média entre o patrimônio líquido de 2010 e o patrimônio líquido de 2009, BONUS é igual a 1 para empresa que pagam bônus aos administradores e 0 em caso contrário, ADR é igual a 1 para empresas que negociam ADR em outros mercados e 0 em outros casos. $* 1 \% * * 5 \% * * * 10 \%$. (a) todas as variáveis apresentaram distribuição não normal. ) b Aplicado à correção de continuidade de Yates (quando um dos grupos possui menos de 5 observações). Fonte: Elaborada pelos autores.

Os dados apresentados na tabela 4 demonstram que as medidas de porte das empresas que adotam o método do custo são maiores (tanto em termos do ativo total quando em relação à receita líquida) do que as empresas que usam valor justo. Observa-se que, em média, a receita líquida das empresas que adotam o método de valor justo (R\$ 317 milhões) é inferior a receita líquida das empresas que adotam o método de custo ( $\mathrm{R} \$ 1.508$ milhões), sendo esta última cinco vezes maior que a primeira.

A análise do teste de diferença de média indica que existem diferenças estatisticamente significativas apenas para a variável "porte", das empresas que adotam o método de custo e das empresas que adotam o método do valor justo, quando mensurado pelo logaritmo da Receita Líquida do exercício de 2010. Nesse caso, rejeita-se $\mathrm{H}_{0}$ ao nível de significância de 5\%.

Em relação às medidas de endividamento, tanto o Div1 (Passivo Exigível de 2010 dividido pelo patrimônio líquido de 2010) quanto o Div2 (Ativo Total de 2010 dividido pelo patrimônio líquido de 2010) apontam que as empresas que utilizam o método do custo possuem níveis de endividamento maiores que as empresas que utilizam o método do valor justo.

A situação é inversa em relação às medidas de rentabilidade. Tanto o Retorno sobre Patrimônio Líquido (ROE) quanto o Retorno sobre o Ativo (ROA) das empresas que adotam o método de valor justo é maior que as empresas que usam o método de custo, mostrando que essas empresas possuem uma rentabilidade maior.

Em relação às medidas de endividamento e rentabilidade, o teste estatístico aponta que não se deve rejeitar $\mathrm{H}_{0}$ (ao nível de significância de $10 \%$ ), ou seja, não há diferença estatisticamente significativa dessas variáveis entre as empresas que utilizam o método de custo e as empresas que utilizam o método do valor justo para mensuração das propriedades para investimento.

Sobre as variáveis qualitativas, a tabela demonstra que 28 empresas da amostra $(77,7 \%)$ utilizam plano de remuneração variável para seus administradores, sendo esta uma prática predominante tanto nas empresas que utilizam o custo como nas empresas que utilizam o valor justo. Já em relação à participação em bolsas de valores estrangeiras, somente 4 empresas da amostra $(12,5 \%)$ negociam suas ações em bolsas estrangeiras, sendo que 3 delas utilizam o método do custo e 1 utiliza o método do valor justo. Também para estas variáveis, não há diferença estatisticamente significativa (ao nível de significância de 10\%).

A tabela 5 apresenta o resultado do teste de proporção, para as empresas que utilizaram o método do valor justo, entre a quantidade de empresas que tiveram lucro e que tiveram prejuízo, considerando o resultado do exercício antes e depois dos efeitos do CPC 28.

$\mathrm{O}$ teste de proporções indica que, ao nível de significância de $10 \%$, que não se deve rejeitar $\mathrm{H}_{0}$, ou seja, não existem diferenças na proporção de empresas que utilizam valor justo e tiveram lucro e empresas que utilizam valor justo e tiveram prejuízo de acordo com o resultado considerado (resultado divulgado e resultado ajustado).

Apesar de o teste estatístico apontar que não existem diferenças estatísticas nas proporções, nota-se ao observar a tabela 5 que três das empresas da amostra que avaliaram suas propriedades para investimento a valor justo utilizaram o valor da variação do valor justo para obterem resultado positivo (lucro) no período.

Tabela 5. Análise do resultado das empresas que adotaram o método do valor justo

\begin{tabular}{|c|c|c|c|c|}
\hline \multicolumn{5}{|c|}{ Painel 1 - Teste de Proporção do resultado antes e depois do ajuste pelo valor de Mercado } \\
\hline Tipo & ResultadoDivulgado & Resultado Ajustado ${ }^{a}$ & Total & Teste $^{\mathrm{b}} \chi 2$ \\
\hline Lucro & 13 & 10 & 23 & 0,974 \\
\hline Prejuízo & 1 & 4 & 5 & Sig $=0,334$ \\
\hline Total & 14 & 14 & 28 & \\
\hline \multicolumn{5}{|c|}{ Painel 2- Análise do Resultado antes e depois do ajuste pelo valor de mercado ( $n=14)$} \\
\hline & Resultado Divulgado & Resultado Ajustado ${ }^{\mathrm{a}}$ & Valor Médio do Ajuste (\%) & Teste Wilcoxon ${ }^{\mathrm{c}}$ \\
\hline Média & 146.045 & 26.132 & $-82,1$ & $-2,023$ \\
\hline Mediana & 62.317 & 31.164 & & Sig $=0,043 * *$ \\
\hline Desvio Padrão & 231.932 & 97.605 & & \\
\hline Mínimo & -4.734 & -212.169 & & \\
\hline Máximo & 813.368 & 218.484 & & \\
\hline
\end{tabular}

Nota: (a) O resultado divulgado considerou o resultado divulgado pela empresa na demonstração do resultado. O resultado ajustado foi calculado subtraindo o efeito da variação do valor justo reconhecido no resultado divulgado pela empresa no ano de 2010. (b) Foi aplicada a correção de continuidade de Yates. (c) Testou-se a hipótese nula de que não existem diferenças significativas entre o resultado divulgado e o resultado ajustado das empresas que utilizam o método do valor justo. ** 5\%

Fonte: Elaborada pelos autores. 
Ao analisar a variação do valor justo reconhecida no resultado das empresas, percebe-se que, no ano de 2010 , todas as variações foram positivas, tendo um valor médio de R\$ 279 milhões. Além disso, nota-se que a média do resultado ajustado é $82,1 \%$ menor que a média do resultado divulgado, demonstrando que o resultado divulgado é maior que o resultado sem o ajuste pelo valor de mercado. Destaca-se que essa diferença de médias é estatisticamente significativa (ao nível de significância de 5\%), conforme demonstrado pelo teste Wilcoxon.

Essas evidências podem sinalizar, corroborando o teste de diferença de médias apresentado na tabela 4 , que algumas empresas optaram pelo método de mensuração do valor justo para aumentar o seu resultado, e, em alguns casos, alterar o resultado apurado de prejuízo para lucro.

\subsection{Análise Multivariada Utilizando o Modelo de Regressão Logística}

A tabela 6 apresenta os resultados da estatística multivariada, com base no modelo logit proposto.

Através da análise multivariada, ficou constatado que a variável "receita líquida" (mensurada pelo logaritmo da receita líquida de 2010) é uma variável estatisticamente significativa (considerando o nível de significância de $10 \%$ ) para explicar a escolha do método de avaliação das propriedades para investimento. Assim, mantendo as outras variáveis constantes, as empresas com menores receitas têm maior probabilidade para escolher o método do valor justo. Esse resultado corrobora o resultado indicado pelo teste univariado de diferença de média.

Tabela 6. Resultado dos testes do modelo de regressão logística ( $\mathrm{n}=36$ empresas)

\begin{tabular}{|c|c|c|c|c|c|c|c|c|}
\hline \multicolumn{9}{|c|}{$\operatorname{logit}(p)=\beta_{0}+\beta_{1}$ Porte $+\beta_{2}$ Dívida $+\beta_{3}$ Rentabilidade $+\beta_{4}$ Bonus $+\beta_{5}$ ADR $+\varepsilon$} \\
\hline Variáveis & Modelo 1 & Modelo 2 & Modelo 3 & Modelo 4 & Modelo 5 & Modelo 6 & Modelo 7 & Modelo 8 \\
\hline Constante & $\begin{array}{c}6,938 \\
{[0,137]}\end{array}$ & $\begin{array}{c}5,904 \\
{[0,075]^{* * *}}\end{array}$ & $\begin{array}{c}6,925 \\
{[0,127]}\end{array}$ & $\begin{array}{c}6,106 \\
{[0,082]^{* * *}}\end{array}$ & $\begin{array}{c}6,888 \\
{[0,128]}\end{array}$ & $\begin{array}{c}6,083 \\
{[0,083]^{* * *}}\end{array}$ & $\begin{array}{c}6,929 \\
{[0,138]}\end{array}$ & $\begin{array}{c}5,860 \\
{[0,076]^{* * *}}\end{array}$ \\
\hline LOG_AT & $\begin{array}{l}-1,147 \\
{[0,141]}\end{array}$ & & $\begin{array}{l}-1,132 \\
{[0,135]}\end{array}$ & & $\begin{array}{l}-1,120 \\
{[0,138]}\end{array}$ & & $\begin{array}{l}-1,143 \\
{[0,143]}\end{array}$ & \\
\hline LOG_REC & & $\begin{array}{c}-1,056 \\
{[0,077]^{* * *}}\end{array}$ & & $\begin{array}{c}-1,109 \\
{[0,080]^{* * *}}\end{array}$ & & $\begin{array}{c}-1,106 \\
{[0,081]^{* * *}}\end{array}$ & & $\begin{array}{c}-1,1053 \\
{[0,078]^{* * *}}\end{array}$ \\
\hline DIV1 & $\begin{array}{c}-0,028 \\
{[0,360]}\end{array}$ & & $\begin{array}{c}-0,048 \\
{[0,365]}\end{array}$ & & & $\begin{array}{l}-0,016 \\
{[0,764]}\end{array}$ & & $\begin{array}{c}-0,037 \\
{[0,460]}\end{array}$ \\
\hline DIV2 & & $\begin{array}{c}-0,035 \\
{[0,459]}\end{array}$ & & $\begin{array}{l}-0,015 \\
{[0,773]}\end{array}$ & $\begin{array}{c}-0,045 \\
{[0,358]}\end{array}$ & & $\begin{array}{l}-0,026 \\
{[0,614]}\end{array}$ & \\
\hline ROA & & $\begin{array}{c}5,337 \\
{[0,307]}\end{array}$ & $\begin{array}{c}5,160 \\
{[0,301]}\end{array}$ & & $\begin{array}{c}5,069 \\
{[0,310]}\end{array}$ & & & $\begin{array}{c}5,410 \\
{[0,301]}\end{array}$ \\
\hline ROE & $\begin{array}{c}4,233 \\
{[0,267]}\end{array}$ & & & $\begin{array}{c}4,628 \\
{[0,253]}\end{array}$ & & $\begin{array}{c}4,609 \\
{[0,254]}\end{array}$ & $\begin{array}{c}4,270 \\
{[0,264]}\end{array}$ & \\
\hline BONUS & $\begin{array}{c}-0,997 \\
{[0,323]}\end{array}$ & $\begin{array}{c}-0,727 \\
{[0,447]}\end{array}$ & $\begin{array}{c}-0,748 \\
{[0,425]}\end{array}$ & $\begin{array}{l}-1,022 \\
{[0,328]}\end{array}$ & $\begin{array}{c}-0,739 \\
{[0,430]}\end{array}$ & $\begin{array}{l}-1,023 \\
{[0,327]}\end{array}$ & $\begin{array}{c}-0,996 \\
{[0,323]}\end{array}$ & $\begin{array}{c}-0,972 \\
{[0,442]}\end{array}$ \\
\hline ADR & $\begin{array}{c}-0,562 \\
{[0,662]}\end{array}$ & $\begin{array}{c}-0,986 \\
{[0,489]}\end{array}$ & $\begin{array}{l}-0,667 \\
{[0,601]}\end{array}$ & $\begin{array}{c}-0,554 \\
{[0,663]}\end{array}$ & $\begin{array}{c}-1,080 \\
{[0,475]}\end{array}$ & $\begin{array}{c}-0,546 \\
{[0,668]}\end{array}$ & $\begin{array}{c}-0,581 \\
{[0,651]}\end{array}$ & $\begin{array}{c}-0,972 \\
{[0,495]}\end{array}$ \\
\hline $\begin{array}{c}-2 \text { Log } \\
\text { likelihood }\end{array}$ & 42,447 & 41,700 & 43,013 & 41,467 & 43,110 & 41,456 & 42,961 & 41,658 \\
\hline Cox \& Snell $\mathrm{R}^{2}$ & 0,146 & 0,163 & 0,132 & 0,169 & 0,130 & 0,169 & 0,133 & 0,164 \\
\hline Nagelkerke $\mathrm{R}^{2}$ & 0,198 & 0,221 & 0,179 & 0,229 & 0,176 & 0,229 & 0,181 & 0,223 \\
\hline
\end{tabular}

Nota: Na variável dependente foi atribuído 0 (zero) para empresas que utilizam o método do custo e 1 (um) para empresas que utilizam o método do valor justo. Log_At é o logaritmo do Ativo Total de 2010, Log_Rec é o logaritmo da Receita Líquida de 2010, Div1 é o Passivo Exigível de 2010 dividido pelo patrimônio líquido de 2010; Div2 é o Ativo Total de 2010 dividido pelo patrimônio líquido de 2010 ; ROA é o Lucro Líquido de 2010 dividido pela média entre o ativo total de 2010 e o ativo total de 2009; ROE é o Lucro Líquido de 2010 dividido pela média entre o patrimônio líquido de 2010 e o patrimônio líquido de 2009, BONUS é igual a 1 para empresa que pagam bônus aos administradores e 0 em caso contrário, ADR é igual a 1 para empresas que negociam ADR em outros mercados e 0 em outros casos. Foram utilizados os valores do Ativo Total de 2010 e da Receita Líquida de 2010, ao invés do Log_At e Log_Rec, porém os resultados foram os mesmos. $* 1 \% * * 5 \% * * * 10 \%$. Elaborada pelos autores.

Em relação às outras variáveis, não foram encontradas evidências estatísticas de que as mesmas influenciem a escolha do método de mensuração das propriedades para investimento. Essa afirmação é válida para as variáveis ativo total, rentabilidade (ROE e ROA), negociação em outros mercados (ADR), endividamento (DIV1 e DIV2) e para pagamento de remuneração variável aos administradores (BONUS).

Sendo assim, ao contrário do que foi encontrado por Conceição (2009) e Christensen e Nikolaev (2009), o nível de endividamento não foi uma variável estatisticamente significativa para influenciar a escolha do método de mensuração das propriedades para investimento.

Os resultados obtidos na regressão logística são próximos aos encontrados por Conceição (2009). Em seu estudo foram encontradas evidências estatísticas que o porte da empresa é uma variável significativa para a adoção do valor justo, porém a variável utilizada pela autora foi o total dos ativos, enquanto que no presente estudo a variável (estatisticamente significativa) utilizada para representar o porte foi o logaritmo da receita total do exercício.

Considerando que o efeito do ajuste pela adoção do valor justo foi positivo no ano de 2010 e que tal ajuste não tem impacto tributário, observa-se uma tendência de que empresas com menor receita líquida (medida pelo logaritmo) utilizem o método de valor justo para mensurar as propriedades de investimento para aumentar o resultado. Tal resultado é consistente com a hipótese dos 
planos de incentivo (apesar de não ser estatisticamente significativo nos modelos testados), já que se o resultado for uma dos elementos do plano de incentivo, esse ajuste positivo aumenta a chance de os administradores atingirem suas metas baseadas em resultado.

Por outro lado, o sinal negativo da variável receita líquida também é consistente com a hipótese do risco político. As empresas com maior porte (representado pelo logaritmo da receita líquida) optaram em geral pelo método do custo para minimizar o risco político. Destaca-se ainda que os administradores de empresas com menor receita líquida puderam optar pelo método de valor justo sem impactar a receita líquida e ao mesmo tempo aumentar o resultado líquido, e, eventualmente, maximizar os seus bônus.

\subsection{Nivel de Conformidade Das Empresas Com a Evidenciação Requerida Pelo CPC 28}

A tabela 7 apresenta a descrição do nível de conformidade das empresas em relação às exigências de evidenciação do CPC 28.

Em relação às empresas que adotam o método de custo, como pode ser observado, apenas duas empresas não indicaram explicitamente o método de mensuração de suas propriedades para investimento. As empresas que não o fizeram classificaram suas propriedades para investimento na conta outros investimentos, que é mensurado pelo método de custo.

Tabela 7. Análise do nível de evidenciação das empresas em relação ao exigido pelo CPC 28

\begin{tabular}{|c|c|c|c|c|c|c|c|c|c|c|c|c|c|}
\hline Método & $\underline{\mathbf{N}}$ & \multicolumn{2}{|c|}{$\begin{array}{l}\text { Indicaram o } \\
\text { Método }\end{array}$} & \multicolumn{2}{|c|}{$\begin{array}{l}\text { Divulgaram } \\
\text { Valor Justo }\end{array}$} & \multicolumn{2}{|c|}{$\begin{array}{l}\text { Divulgaram a } \\
\text { variação } \\
\text { valor justo }\end{array}$} & \multicolumn{2}{|c|}{$\begin{array}{c}\text { Dedicam Nota } \\
\text { Explicativa }\end{array}$} & \multicolumn{2}{|c|}{$\begin{array}{l}\text { Divulgaram } \\
\text { Método de mensuração } \\
\text { do valor justo }\end{array}$} & \multicolumn{2}{|c|}{$\begin{array}{l}\text { Declararam } \\
\text { Avaliador } \\
\text { Independente }\end{array}$} \\
\hline Custo & 22 & 20 & $91 \%$ & 15 & $68 \%$ & \multicolumn{2}{|c|}{ N/A } & 16 & $73 \%$ & 11 & $50 \%$ & 11 & $50 \%$ \\
\hline Valor Justo & $\underline{14}$ & $\underline{14}$ & $100 \%$ & $\underline{14}$ & $\underline{100 \%}$ & $\underline{5}$ & $\underline{36 \%}$ & $\underline{14}$ & $\underline{100 \%}$ & $\underline{6}$ & $\underline{43 \%}$ & $\underline{7}$ & $\underline{50 \%}$ \\
\hline
\end{tabular}

Notas: O percentual foi calculado tendo como base o total de empresas. N/A - Não aplicável.

Fonte: Elaborado pelos autores.

Entre as empresas que optaram pelo método de custo, $68 \%$ delas não divulgaram o valor justo de suas propriedades para investimento conforme exigido pelo CPC 28. Destaca-se ainda que seis empresas $(27 \%$ do total) não divulgaram nota explicativa sobre suas propriedades para investimento conforme determina a norma.

Em relação às empresas que optaram pelo método do valor justo, apenas 5 (cinco) empresas divulgaram as variações do valor justo no resultado do período em notas explicativas. Nos demais casos, a variação foi incluída na demonstração do resultado, porém não era possível identificar qual o valor exato dessa variação. Deve-se ressaltar que 2 (duas) empresas não divulgaram a variação no resultado porque começaram a operar com propriedades para investimento no ano de 2010.

De acordo com o CPC 28, todas as empresas que possuem propriedades para investimento devem calcular o valor justo das mesmas. Porém, apenas 18 (47\% do total, isto é, menos da metade) das empresas da amostra divulgaram em suas notas explicativas quais foram as premissas adotadas pela empresa para a obtenção do valor justo. O CPC 28 também recomenda que o valor justo seja obtido com base em avaliação feita por avaliadores independentes, sendo que metade das empresas da amostra declarou a contratação de tal agente para mensurar o valor justo de suas propriedades.

Em resumo, observa-se que o nível de conformidade em relação ao exigido para divulgação em notas explicativas pelo CPC 28, está abaixo do ideal em algumas empresas analisadas, sendo que as empresas que adotam o método do custo apresentam um menor grau de conformidade se comparadas com as empresas que utilizam o método do valor justo. $\mathrm{O}$ fato de que o exercício de 2010 é o primeiro ano de aplicação de todos os Pronunciamentos Técnicos emitidos pelo Comitê de Pronunciamentos Técnicos pode explicar em parte as deficiências de evidenciação nas notas explicadas observadas.

Um das explicações possíveis para esse baixo grau de conformidade na divulgação das empresas podem estar relacionado com as dificuldades de implementação das novas normas contábeis decorrentes de sua complexidade e/ou do grande número de mudanças introduzidas.

\section{CONSIDERAÇÕES FINAIS}

O objetivo do artigo foi analisar os incentivos econômicos para seleção do método (custo ou valor justo) de mensuração contábil das propriedades para investimento por parte das empresas brasileiras não financeiras de capital aberto. Adicionalmente, como objetivo secundário da pesquisa, buscou-se (a) identificar as empresas impactadas pelo CPC 28, e seus respectivos setores de atividades; (b) demonstrar o método contábil preferido pelas empresas para avaliação de suas propriedades para investimento; e (c) analisar a qualidade da evidenciação contábil vis-à-vis a exigência mínima de divulgação estabelecida no CPC 28.

No desenvolvimento do presente estudo foram analisadas as demonstrações contábeis, e respectivas notas explicativas, das empresas de capital aberto arquivadas no site da Comissão de Valores Mobiliários (CVM). A análise dos dados compreendeu a aplicação de testes estatísticos univariados e multivariados para a análise quantitativa dos dados, bem como, para a análise qualitativa das informações divulgadas.

O estudo constatou que apenas 36 empresas de capital aberto ( $11 \%$ do total) foram impactadas pelo CPC 28 no exercício de 2010, sendo que apenas 39\% das empresas (14 empresas) optaram pela adoção do método de valor 
justo para mensurar suas propriedades para investimento. O baixo percentual de adoção do método de valor justo observado está próximo ao apurado em países como Alemanha, França e Portugal, o que indica que no Brasil, assim como nesses países, ainda há uma preferência pela adoção do método de custo histórico.

Os setores de atividades com o maior número de empresas impactadas foram: (a) têxtil (7 empresas); (b) administração de empresas e empreendimentos (6 empresas); (c) construção (6 empresas); e (d) locadora de imóveis (5 empresas). Entre os 20 setores de atividades analisados, verificou-se que nove setores de atividades não foram impactos pelo $\mathrm{CPC} 28$, e apenas o setor "locadora de imóveis" teve todas as empresas impactadas pela nova norma.

Verificou-se também que dentro dos setores econômicos analisados existem empresas que utilizam métodos de mensuração diferentes para o mesmo tipo de ativo. Destaca-se aqui um potencial problema de comparabilidade das demonstrações contábeis de empresas do mesmo setor que adotam práticas contábeis distintas para o mesmo tipo de ativo.

$\mathrm{Na}$ análise dos incentivos econômicos para a escolha do método contábil de mensuração das propriedades para investimento, o teste multivariado (regressão logística) demonstrou que apenas o porte da empresa, medido pelo logaritmo da receita líquida do exercício, é estatisticamente significativo (ao nível de significância de 5\%) para determinar a escolha do método de mensuração das propriedades para investimento. Assim, as empresas com menor receita líquida no exercício de 2010 apresentam maior chance de adotar o método do valor justo (que provocou um ajuste médio positivo no resultado) em comparação com as empresas que optaram pelo método de custo. Em geral, as empresas que adotaram o método do valor justo apresentaram uma receita líquida de $\mathrm{R} \$ 1.035$ milhões, enquanto as empresas que adotaram o método de custo apresentaram uma receita líquida de R $\$ 1.508$ milhões. Destaca-se ainda que os resultados na análise multivariada são consistentes com os resultados dos testes de diferença de médias (Mann-Whitney $U$ ) aplicados.

Os dados analisados também demonstram que as empresas que optaram pelo método do valor justo apresentam, em média, menor endividamento, maior rentabilidade, utilizam com menor frequência um plano de remuneração variável para seus administradores, e têm um menor número de casos de ações listadas nas bolsas internacionais, se comparadas às empresas que adotam o método do custo. No entanto, nenhuma das características mencionadas apresentou uma diferença estatisticamente significativa (ao nível de significância de $10 \%)$.

$\mathrm{Na}$ análise dos efeitos dos ajustes decorrentes da adoção do método do valor justo pelas empresas, o teste estatístico (teste qui-quadrado para uma tabela de contingência) demonstrou que não existem diferenças estatísticas nas proporções de empresas com lucro ou prejuízo apurado antes e depois do efeito do reconhecimento dos ganhos pela adoção do método. Apesar de a diferença não ser estatisticamente significativa, observou-se que todas as variações decorrentes da adoção do método de valor justo foram positivas, tendo um valor médio de R \$ 279 milhões. Tal situação permitiu que três empresas obtivessem lucro no exercício de 2010 com o ajuste positivo decorrente da adoção do método de valor justo.
Os resultados obtidos na regressão logística são próximos aos encontrados por Conceição (2009), que encontrou evidências de que o porte da empresa (medido pelo total de ativos) é uma variável estatisticamente significativa para a adoção do método do valor justo. No presente estudo, a variável (estatisticamente significativa) utilizada para representar o porte foi o logaritmo da receita total do exercício. Diferentemente do constatado por Conceição (2009) e Christensen e Nikolaev (2009), o nível de endividamento não foi uma variável estatisticamente significativa para influenciar a escolha do método de mensuração das propriedades para investimento.

Considerando que o efeito do ajuste pela adoção do valor justo foi positivo no ano de 2010 e que tal ajuste não tem impacto tributário, observa-se uma tendência de que empresas com menor receita líquida (medida pelo logaritmo) utilizem o método de valor justo para mensurar as propriedades de investimento de modo a aumentar o resultado. Destaca-se ainda que os administradores de empresas com menor receita líquida puderam optar pelo método de valor justo sem impactar a receita líquida e ao mesmo tempo aumentar o resultado líquido, e, eventualmente, maximizar os seus bônus. Tal resultado é consistente com a hipótese dos planos de incentivo (apesar de não ser estatisticamente significativo nos modelos testados). Por outro lado, o sinal negativo da variável "receita líquida" também é consistente com a hipótese do risco político. As empresas com maior porte (representado pelo logaritmo da receita líquida) optaram em geral pelo método do custo para minimizar o risco político.

Em relação ao atendimento da divulgação mínima em notas explicativas fixada pelo CPC 28 , observou-se que, em geral, o nível de conformidade está abaixo do ideal em algumas empresas analisadas, sendo que as empresas que adotam o método do custo apresentam como principais deficiências: (a) não divulgação do valor justo de suas propriedades para investimento em notas explicativas (68\% dos casos), (b) não divulgação de uma nota explicativa sobre suas propriedades para investimento ( $27 \%$ do total); e (c) classificação de suas propriedades para investimento no grupo "outros investimentos" (dois casos). No caso das empresas que adotaram o método do valor justo, as principais deficiências identificadas foram: (a) não divulgação em notas explicativas das variações do valor justo reconhecidas no resultado do período $(64 \%$ dos casos); e (b) não divulgação em notas explicativas das premissas adotadas pela empresa para a obtenção do valor justo (57\% dos casos).

Notadamente, o não cumprimento dos requisitos mínimos de divulgação das informações sobre as propriedades para investimento (especialmente em relação a não divulgação do valor justo) pode dificultar a comparabilidade entre os dados contábeis divulgados pelas empresas. É importante lembrar que o exercício de 2010 foi o primeiro ano de aplicação de todos os Pronunciamentos Técnicos, emitidos pelo Comitê de Pronunciamentos Técnicos, o que pode explicar, em parte, as deficiências de evidenciação em notas explicadas observadas.

O presente estudo é relevante por dois aspectos principais:

(a) apresenta evidências complementares (à linha de pesquisa accounting choice) sobre a escolha de práticas contábeis realizadas pelos administradores de empresas no Brasil 
após a adoção das normais internacionais de contabilidade, demonstrando os incentivos econômicos que influenciam as empresas a adotarem determinadas práticas dentro desse novo cenário contábil; e

(b) permite conhecer os principais aspectos da implementação do CPC 28 (Propriedades para Investimento) no primeiro ano de adoção integral das normas internacionais de contabilidade.

\section{REFERÊNCIAS BIBLIOGRÁFICAS}

CHRISTENSEN, H. B.; NIKOLAEV, V. Who uses fair value accounting for non-financial assets after IFRS adoption. Working Paper. Chicago Business School. p.1-46, 2009

COMITE DE PRONUINCIAMENTOS CONTÁBEIS. CPC 28 - Propriedades para Investimento. Disponível em $<$ http://www.cpc.com.br>. Acessado em $16 / 12 / 2011$

CONCEIÇÃO, L. C. P. A Opção Pelo “Justo Valor" Como Método De Avaliação De Activos Na Adopção Das Ias/Ifrs Em Portugal: Uma Análise Exploratória. 2009. 81 f. Dissertação (Mestrado) - Departamento de Faculdade de Economia, Universidade do Porto, Porto.

DEMARIA, S.; DUFOUR, D. First time adoption of IFRS, Fair value option, Conservatism: Evidences from French listed companies. 2008. Disponível em <http://hal.archives-ouvertes.fr/ docs/00/26/61/89/PDFFirst_adoption_and_fair_ value Demaria Dufour.pdf $>$. Acessado em $19 \mathrm{Dez}$ 2011.

FIELDS, T.; LYS, T.; VINCENT, L. Empirical Research on Accounting Choice. Journal Of Accounting And Economics, v. 31, n. , p.255-307, 2001.

HAIR, J. F.; ANDERSON, R. E.; TATHAM, R. L.; BLACK, W. C. Análise multivariada de dados. Tradução de Adonais Schlup Sant'anna e Anselmo Chaves Neto. 5. ed. Porto Alegre: Bookman, 2005.

INTERNATIONAL ACCOUNTING STANDARDS BOARD - IASB. Basis for Conclusions on IAS 40 Investment Property. Londres, 2009

MULLER III, K. A.; RIEDL, E. J; SELLHORN, T. Causes and consequences of choosing historical cost versus fair value: Disponível em $<\mathrm{http}$ :// www3.nd.edu/ carecob/May2008Conference/ Papers/RiedlMRS03062008.pdf>. Acessado em 19 Dez 2011

RONEN, J.; YAARI, V. EARNINGS MANAGEMENT: Emerging Insights in Theory, Practice, and Research. . Springer, 2008.

SILVA, A. H. C. Escolha De Práticas Contábeis No Brasil: Uma Análise Sob A Ótica Da Hipótese Dos Covenants Contratuais. 2008. 151 f. Tese (Doutor) - USP, São Paulo.

SILVA, A. H. C.; SANCOVSCHI, M. Mudanças De Práticas Contábeis Em Empresas Privatizadas: Estudo De Casos No Segmento De Serviços Públicos De Distribuição De Gás. In: CONGRESSO ANPCONT, 2., Gramado/RS. Anais... Anpcont, 2007.

WATTS, R. L.; ZIMMERMAN, J. L.. Positive Accounting Theory: A Ten Year Perspective. The Accounting Review, p. 131-156. jan. 1990.

\section{AGRADECIMENTOS:}

O presente artigo recebeu importantes contribuições dos professores José Alonso Borba, Álvaro Vieira Lima, José Augusto Veiga da Costa Marques, Marcelo Álvaro da Silva Macedo e dos demais participantes do I Workshop em Contabilidade Financeira realizado em março de 2012, na Universidade do Estado do Rio de Janeiro. 